\title{
Effects of Antihypertensive Drugs on Blood Velocity: Implications for Prevention of Cerebral Vascular Disease
}

\author{
J. DAVID SPENCE
}

SUMMARY: The treatment of high blood pressure prevents death from congestive heart failure, hypertensive nephropathy, and encephalopathy, and strokes from cerebral arteriolar disease (lacunes, hemorrhage from microaneurysms). However, atherosclerosis, manifested as coronary artery disease, is just as frequent a cause of death in well-controlled hypertensives as in poorly-controlled patients. Increasing evidence suggests that increased blood velocity, by causing turbulence and high shear rates at the endothelial surface of arteries, may be important in the pathogenesis of atherosclerosis. Turbulence has been observed in cerebral berry aneurysms. In order to measure the

RÉSUMÉ: Le traitement de l'hypertension protège de l'insuffisance cardiaque, de la néphropathie hypertensive, de l'encéphalopathie hypertensive et des accidents cérébro-vasculaires (lacunaires, hémorragie consécutive à des micro-anévrismes). Cependant, l'athérosclérose, manifestée par une maladie de l'artère coronaire, est une cause de décès aussi fréquente chez les patients hypertendus bien contrôlés que chez les patients moins bien contrôlés. De plus en plus d'évidence s'accumule montrant que la vélocité accrue du sang, en causant de la turbulence et un taux élevé de petites déchirures à la surface endothéliale des artères, peut être importante dans la pathogénèse de l'athérosclérose. La turbulence a été observée dans certains anévrismes. cérébraux.

This work was carried out while the author was the recipient of an Ontario Ministry of Health Fellowship.

The work was conducted in the Division of Clinical Pharmacology and Cardiovascular Research Institute, University of California, San Francisco.

This paper was given as the Francis McNaughton Prize Essay of the Canadian Neurological Society, in Winnipeg, Manitoba, October 14, 1976. It was abstracted in Canad. J. Neurol. Sci. 3: 149, 1976.

Reprint requests to Dr. J. David Spence, Departments of Medicine and Clinical Neurological Sciences, University of Western Ontario, Victoria Hospital, London, Ontario, Canada, N6A 4G5. effects of antihypertensive agents on blood velocity, a new method of analysing Doppler ultrasound velocity recordings has been developed. Studies in Rhesus monkeys show the following: In doses which reduce diastolic pressure by $13-28 \%$, propranolol decreased mean blood velocity $(\mathrm{MV})$ by $17 \%$, clonidine decreased $M V$ by $14 \%$, while methyldopa increased $M V 12 \%$, and hydralazine increased $M V$ by $52 \%$. $(p<.00001)$. It is hypothesized that enlargement of berry aneurysms, the progression of cerebral atherosclerosis, and embolism from carotid lesions might all be decreased by the selection of antihypertensive agents which decrease blood velocity.

Afin de mesurer les effets des agents antihypertensifs sur la vélocité du sang, une nouvelle méthode d'analyse Doppler de la vitesse des ultrasons a été développée. Des études sur les singes Rhesus montrent les faits suivants: aux doses qui diminuent la pression diastolique de 13-28\%, le Propanolol diminuait la vélocité moyenne du sang (MV) de $17 \%$, la Clonidine diminuait $M V$ de $14 \%$, tandis que la Methyldopa diminuait $M V$ de $12 \%$, et l'Hydralazine augmentait $M V$ de $52 \%(p<.00001)$. La progression de l'athérosclérose cérébrale, le mécanisme embolique des lésions de la carotide et l'agrandissement des microanévrismes pourraient tous être diminués par une sélection d'agents antihypertensifs qui diminuent la vélocité du sang
Neurogists recognize that hypertension is an important factor in the pathogenesis of stroke. Treatment of hypertension is known to prevent stroke in patients who have not yet had a stroke (Veteran's Administration Cooperative Study Group on Antihypertensive Agents, 1975), and to prevent recurrence in hypertensive patients who have already had a stroke (Beevers et al., 1973). However, the mechanism by which increased pressure causes strokes, and by which the treatment of increased pressure prevents strokes, is commonly ignored.

Stroke (vascular disease resultıng in brain infarction or intracerebral hemorrhage) can result from disease of arteries or arterioles. Both arteriolar disease (lacunar infarction and hemorrhage from cerebral microaneurysm (Charcot and Bouchard, 1868; Russell, 1963; Cole and Yates, 1967) and arterial disease (atherosclerosis) may be related to hypertension. However, there is no a priori reason to assume that both kinds of disease are related to the same kind of increased energy in the circulating blood.

It has become clear that the vascular disease which occurs as a result of increased pressure is arteriolar disease, and the treatment of increased pressure does not prevent disease of larger arteries. Dustan (1974) and Russell (1975) have each recently suggested that the prevention of stroke in hypertension is due to the prevention of hemorrhage from microaneurysms, and prevention of lacunar strokes caused by hypertensive disease of arterioles.

Although increased blood pressure is important in the pathogenesis of atherosclerosis (Dustan, 1974; Kannel et al., 1971), through effects 
TABLE 1

VASCULAR EFFECTS OF "HYPERTENSION"

\author{
Effects of Pressure \\ Arteriolar damage: \\ Retinopathy \\ Nephropathy \\ Encephalopathy \\ Cerebral microaneurysms \\ (of Charcot and Bouchard) \\ Congestive Heart Failure
}

\author{
Effects of Flow \\ Arterial damage: \\ Atherosclerotic plaques \\ Intimal cushions, \\ Post-stenotic dilatation \\ Macroaneurysms \\ (berry aneurysms) \\ Embolism \\ From plaques \\ Platelet injury
}

on arterial wall transport (Bergel, 1976), evidence suggests that forces in the circulating blood other than pressure may also be involved in the development of atherosclerotic lesions in arteries.

The studies which show the benefit of treating hypertension demonstrate that patients with wellcontrolled hypertension fare no better than do poorly-controlled patients, with respect to disease of arteries, manifested as coronary artery disease (Beevers et al., 1973; Taguchi et al., 1974). The management of hypertension has been based on the assumption that diastolic hypertension is more serious than systolic hypertension. However, it was recognized in the Framingham study that systolic hypertension was more strongly correlated with coronary artery disease than diastolic hypertension (Kannel et al., 1971).

The above observations raise the possibility that some form of energy other than increased pressure, but associated with hypertension, might be responsible for arterial disease. Specifically, is there any association of disturbed flow with forces which might cause atherosclerosis?

The total energy of the circulating blood is composed of the sum of pressure energy and kinetic energy, or flow energy. These two forms of energy can be interconverted. At locations where flow becomes turbulent (non-laminar), pressure energy is converted to kinetic energy, and transmitted to the arterial wall as heat and vibration (Burton, 1972).
These observations have implications for the prevention of cerebral vascular disease. They lead to a perception of hypertension as a disorder of increased energy in the circulating blood, with two aspects: increased pressure has certain consequences in arterioles, while increased velocity in arteries has other consequences. (See table 1). If this is so, then the selection of drugs which lower both pressure and velocity might improve the prevention of cerebrovascular disease in hypertensive patients. This question would be of no interest if all antihypertensive drugs were to lower both pressure and velocity. For these reasons, methods were developed to measure the effects of antihypertensive drugs on blood velocity.

\section{METHODS}

In order to determine the effects of antihypertensive drugs on blood velocity, studies were carried out on Rhesus monkeys, in the Primate Laboratory of the Division of Clinical Pharmacology and Cardiovascular Research Institute, San Fran-

It was desirable to have a noninvasive method of measuring blood velocity which could be used in patients. For this reason, a method was developed which used calculator digitization of a spectral display of the audio output of a Doppler (ultrasound) velocity meter. This method gives useful, accurate, numerical representations of peak velocity, mean velocity, endiastolic cisco, Calfornia. velocity, and systolic acceleration, and can be adapted to non-invasive use in patients.

Blood velocity recordings were obtained with a periarterial cuff 1 $\mathrm{cm}$. below the left carotid bifurcation, using a Parks model 806 directional Doppler meter (Parks Electronics, Beaverton, Oregon). Because of problems of non-linearity at high frequencies with conventional methods, and because conventional Doppler meter voltage signals are averaged signals which falsely depress peak velocity (Woodcock et al., 1972), the audio signal of the Doppler velocity waveform was recorded on a Sony dolbyized cassette recorder. This signal was played into a Sonagraph (Kay Elemetrics, Pine Brook, New Jersey) to create a hard copy spectral display of the signal, which appears as a velocity/time waveform (see Fig. 1 for examples). The velocity waveform was then digitized using a magnetic board online with a Hewlett-Packard 9821 calculator, to generate numerical descriptors of the waveform, including peak height (peak velocity), slope (acceleration), area under the waveform (pulse volume), average height, and endiastolic height. Variability between successive measurements on a given waveform was less than $2 \%$ (coefficient of variation) for all measurements except slope. Because the variability of repeated measurements of slope was $8-10 \%$, all measurements were done in triplicate and meaned. (The program is available from the author on request.) Audio signal calibration was done on the Sonagraph using a $500 \mathrm{~Hz}$. calibration signal. The frequency response of the Sonagraph is linear in the frequencies used $(6$ $\mathrm{Hz} .-16 \mathrm{KHz}$.). This method is adapted from Gosling and King, 1974. A detailed description of this study is in preparation for publication elsewhere.

Four monkeys were made hypertensive by infusion of angiotensin and isoproterenol; pressure-pulse recordings were made from the abdominal aorta. The effects of methyldopa, clonidine, hydralazine, and propranolol were studied. Pressures, heart rate, systolic accelera- 
MONKEY \#1
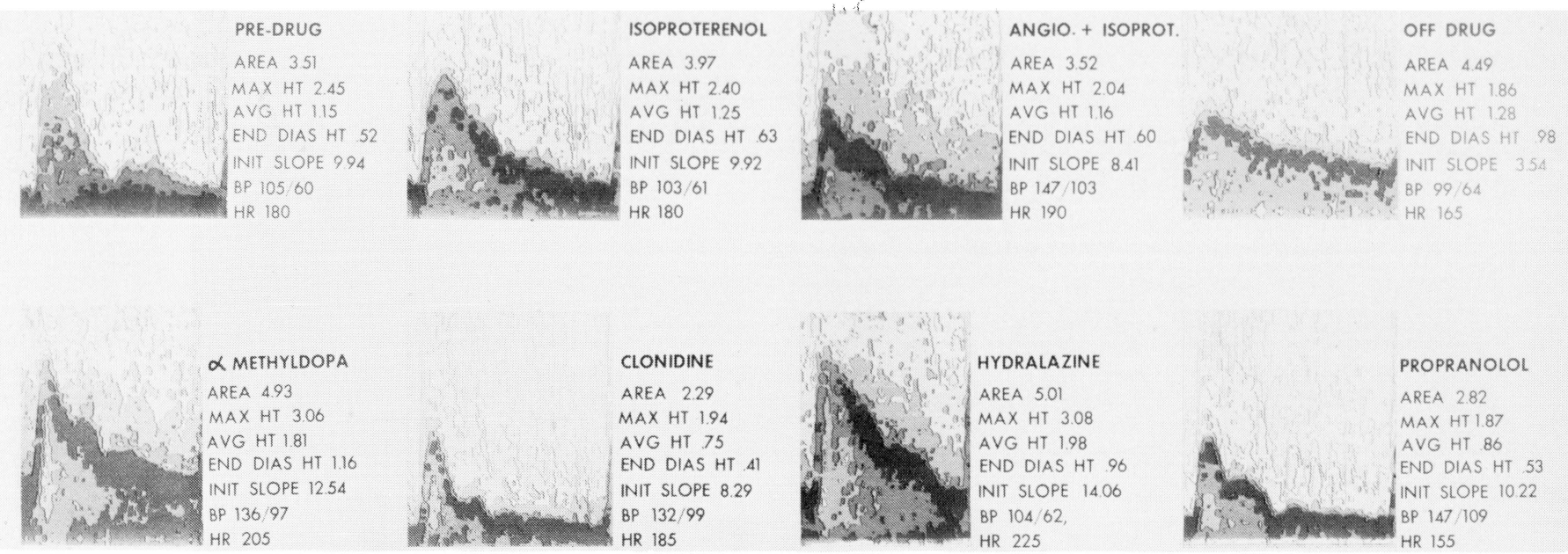

Figure l-AREA, MAX. HT (peak velocity), AVG HT (average velocity), END DIAS. HT (endiastolıc velocity) are measured in inches. BP is blood pressure systolic/diastolic $(\mathrm{mm} \mathrm{Hg})$; $\mathrm{HR}$ is heart rate, beats $/ \mathrm{min}$.

Recordings were made before, during, and after a six week baseline infusion of angiotensin $5 \mathrm{ug} / \mathrm{kg} / \mathrm{min}$. and isoproterenol $20 \mathrm{ug} / \mathrm{kg} / \mathrm{min}$., and during infusion of antihypertensive drugs super-imposed on the hypertensive baseline.

tion, and peak, mean, and endiastolic velocity were measured after boluses of drug and during consecutive increases of infusion rate of drug over 72 hours. The study design was a randomized Latin square crossover design, to eliminate the effect of drug carryover. All monkeys received all four antihypertensive agents. Examples of digitized waveforms are shown in Figure 1.

\section{RESULTS}

The results show that antihypertensive drugs are different in their effects on blood velocity. (See table 2). Propranolol and clonidine both decrease velocity when pressure goes down, while hydralazine and methyldopa both increase blood velocity and flow when pressure decreases. Statistical analyses were done on an IBM 360-50 computer, using subprograms Crosstabs, Partial Corr, and Scattergram of the Statistical package for the Social Sciences (Nie et al., 1975). Chisquare on a two-by-four contingency table (increase vs. decrease of peak velocity for all four drugs in cases where diastolic pressure decreased) gave $p<.00001$ for all four velocity parameters studied. (Peak velocity, mean velocity, endiastolic velocity, acceleration.) Partial correlation analysis was carried out to exclude covariation of the variables measured; in particular, the effects on velocity were not due to effects on heart rate.

\section{DISCUSSION}

This study shows that antihypertensive drugs have different effects on blood velocity. It was easy to predict that propranolol, which decreases cardiac output, would decrease velocity parameters, while hydralazine, which gives rise to reflex tachycardia and increased cardiac output, would increase blood velocity. It was surprising to find that methyldopa and clonidine had opposite effects on blood velocity, and more surprising to observe a differential effect on acceleration compared with peak velocity. The significance of this distinction to the development of turbulence is not known. Yellin (1966) suggested that frequency factors were important in the development of turbulence and in damping of turbulence between cycles. Thus, acceleration might be considered a separate and important feature to be considered in the prediction of turbulence. The importance of localized disturbances of flow in the pathogenesis of athero- sclerosis and cerebral vascular disease is supported by the following observations from the literature. It has been observed that atherosclerotic plaques are not uniformly distributed through the arterial tree. The lesions of atherosclerosis are localized to particular sites in arterial walls, such as bifurcations and the origin of branches (Schwartz et al., 1962). These locations are precisely the places where the movement of blood becomes non-laminar at high velocities, causing turbulence, high shear rates, (high velocity gradients) boundary layer separation, and axial stream impingement (Friedman et al., 1975). Roach et al. (1972) have studied the role of vessel geometry in the genesis of turbulence, and have shown that increasing the angle of bifurcation will cause turbulence to occur at lower velocities. This effect is increased when flow is pulsatile. Roach (1963) has also shown that turbulence, by transmitting vibration to vessel walls, is capable of damaging arteries, and is likely to be responsible for post-stenotic dilatation. Although cerebral berry aneurysms are commonly assumed to be congenital, there is little evidence to support that assumption. Stehbens (1975) has recently reviewed the pathologi- 
TABLE 2

EFFECTS OF ANTIHYPERTENSIVE DRUGS ON BLOOD PRESSURE AND BLOOD VELOCITY

$(M E A N \pm S E)$ PERCENT CHANGE FROM MEAN BASELINE

\begin{tabular}{|c|c|c|c|c|}
\hline \multirow[t]{2}{*}{ VARIABLE } & METHYLDOPA & CLONIDINE & HYDRALAZ INE & PROPRANOLOL \\
\hline & $\mathrm{n}=26$ & $n=39$ & $n=33$ & $n=25$ \\
\hline $\begin{array}{c}\% \Delta \text { Diastolic } \\
\text { Pressure }\end{array}$ & $-13.0 \pm 1.57$ & $-17.9 \pm 2.32$ & $-27.7 \pm 3.01$ & $-17.1 \pm 5.22$ \\
\hline$\% \Delta$ Peak Velocity & $9.3 \pm 2.26$ & $-1.1 \pm 2.09$ & $29.2 \pm 3.71$ & $-17.2 \pm 2.64$ \\
\hline$\% \Delta$ Mean Velocity & $12.4 \pm 3.84$ & $-14.1 \pm 2.83$ & $52.3 \pm 6.81$ & $-15.7 \pm 3.14$ \\
\hline $\begin{array}{l}\% \Delta \text { Endiastolic } \\
\text { Velocity }\end{array}$ & $29.3 \pm 13.04$ & $-22.5 \pm 3.55$ & $42.3 \pm 7.85$ & $-12.4 \pm 3.4$ \\
\hline$\% \Delta$ Acceleration & $-1.1+7.14$ & $16.4 \pm 5.09$ & $35.6 \pm 6.21$ & $-27.7 \pm 5.3$ \\
\hline & & $p<.00001$ & & \\
\hline
\end{tabular}

cal evidence supporting a degenerative pathogenesis for berry aneurysms.

Ferguson (1970) has made intraoperative recordings from patients with intracranial berry aneurysms, and demonstrated the turbulence in the aneurysms. He has suggested that the localization of aneurysms at bifurcations is related to axial stream impingement, while the enlargement of aneurysms is related to turbulence (1972). Fry (1968) has studied the role of flow-related forces in damaging vascular endothelium. He showed that turbulence and high shear were capable of damaging endothelium, whereas pressure is not. Ross and Glomset (1976) have placed the role of endothelila damage in perspective. They showed that endothelial damage initiates the release of soluble platelet factors which result in migration and proliferation of smooth muscle cells in the artery wall. The site of injury becomes a typical atherosclerotic plaque, including deposition of lipid. If the animal is hyperlipidemic, the atherosclerotic plaque persists after a year; if the animal has normal blood lipids, the plaque at the site of experimental injury will heal, beginning about six months after injury, and disappearing at a year (Ross et al.,
1974). According to this scheme. endothelial damage initiates the event. platelets stimulate the formation of a plaque. and elevated blood lipids perpetuate the lesion. Flowrelated forces in the blood are more likely to cause endothelial damage than is elevated pressure; increased blood velocity is more likely to cause activation of platelets and formation of thrombi at stenoses in carotid arteries, and rapid, turbulent flow is more likely than increased pressure to cause embolism from atheromatous ulcers in the carotid arteries.

This discussion focuses on those aspects of hypertension (increased energy in the circulating blood) which relate to localized disturbances of flow, and atherosclerosis. It is not the author's intention to minimize the importance of treating hypertension; quite the contrary. It is merely suggested that the complications of atherosclerosis and berry aneurysms might better be prevented by the selection of antihypertensive drugs which reduce both aspects of increased energy in the circulation: pressure and velocity. Since the methods developed for this study can be adapted to noninvasive use, it will be possible to test this hypothesis in man.

\section{REFERENCES}

BEEVERS. G. D, FAIRMAN, M. J., HAMILTON, M. and HARPUR, J E. (1973). Antihypertensive treatment and the course of established cerebral vascular disease. Lancet, i, 1407-1409.

BERGEL, D. H., NEREM, R. M. and SCHWARTZ, C. J (1976). Fluid dynamic aspects of arterial disease. Atherosclerosis, 23. 253-261

BURTON, A. C. (1972). Kinetic energy in the circulation: streamline flow and turbulence: measurement of arterial pressure. Chap. 11, in Physiology and biophysics of the circulation. Chicago Yearbook Medical Publishers.

CHARCOT, J. M. and BOUCHARD, C. (1868) Nouvelles recherches sur la pathogenie de l'hemorrhagie cerebrale. Archives de Physiologie. 1. 110, 643, and 725 .

COLE. F M. and YATES. P.O. (1967). The occurrence and significance of intracerebral microaneurysms. J Path. Bact., 93, 393.

DUSTAN, H. P Atherosclerosis complicating hypertension. Circulation, 50, 871-879

FERGUSON, G. G. (1972). Physical factors in the initiation, growth, and rupture of human intracranial saccular aneurysms. J Neurosurg.. 37. 666-677

FERGUSON, G. G. (1970). Turbulence in human intracranial saccular aneurysms. J. Neurosurg.. 33. 485-497

FRIEDMAN, M. H., O'BRIAN, $V$ and EHRLICH. L. W (1975). Calculations of Pulsatile Flow Through a branch. Circ. Res., 36, 277-284.

FRY. D. L. (1968). Acute vascular endothelial changes associated with increased blood velocity gradients. Circ. Res., 22, 165-197

GOSLING, R. and KING, D. H. (1974). Continuous wave ultrasound as an alternative and complement to $\mathrm{x}$-rays in vascular examination. In Reneman, R. S. (Ed). Cardiovascular applications of ultrasound. New York, American Elsevier Publishing Co., pp. 266-285.

KANNELL, W B., GORDON, T and SCHWARTZ, M. J. (1971). Systolic versus diastolic blood pressure and risk of coronary heart disease. Am. J Cardiol.. 27, 335-345.

NIE, N. H., HULL, C. H., JENKINS, J G. STEINBRENNER, K. and BENT, D. (1975). Statistical package for the social sciences. 2nd Edition. McGraw-Hill, New York.

ROACH, M. R. (1963). An experimental study of the production and time course of poststenotic dilatation in the femoral and carotid arteries of adult dogs. Circ. Res., 13, 537-551

ROACH, M. R., SCOTT, S. and FERGUSON, G. G. (1972). The hemodynamic importance of the gemometry of bifurcations in the circle of Willis. (Glass Model studies). Stroke, 3, 255-267

ROSS, R. and GLOMSET, J A. (1974). Studies of primate arterial smooth muscle cells in relation to atherosclerosis. In Arter- 
ial Mesenchyme and Arteriosclerosis. Eds. W S. Wagner and T B. Clarkson. Plenum Publ. Corp., New York, pp. 265-279.

ROSS, R. and GLOMSET, J. A. (1976). The pathogenesis of atherosclerosis. N Engl. J. Med., 295, 369-377, 420-425.

RUSSELL, R. W R. (1963). Observations on intracerebral aneurysms. Brain, 86. 425-443.

RUSSELL, R. W R. (1975). How does high blood pressure cause stroke? Lancet, ii, 1283-1285
SCHWARTZ, C J. and MITCHELI, J. R. A. (1962). Observations on localization of arterial plaques. Circ. Res., 11. 63-73.

STEHBENS, W F. (1975). Ultrastructure of aneurysms. Arch. Neurol., 32, 798-807

TAGUCHI, J. and FREIS, E. D. (1974). Partial reduction of blood pressure and prevention of complications in hypertension. New Engl. J. Med., 291, 329-331

VETERAN'S ADMINISTRATION COOPERATIVE STUDY GROUP ON ANTIHYPERTENSIVE AGENTS.
(1975) Effects of treatment on Morbidity in Hypertension. J A.M.A., 213, 11431152.

WOODCOCK, J , GOSLING, R., KING, D. et al. (1972). Physical aspects of bloodvelocity measurement by Doppler-shifted ultrasound. In Roberts. C (Ed). Blood Flow measurement. London, Sector Publishing. pp. 19-23.

YELLIN, E. L. (1966). Laminar-turbulent transition process in pulsatile flow Circ. Res. 19: 791-804 